\title{
Characterization and Optimization of Thermally Grown Iridium Oxide and Its Application to $\mathrm{pH}$ Sensors
}

\author{
Chindanai Ratanaporncharoen, ${ }^{1}$ Miyuki Tabata, ${ }^{1}$ \\ Natthapol Watanagool, ${ }^{2}$ Tatsuro Goda, ${ }^{1}$ \\ Akira Matsumoto, ${ }^{1}$ Mana Sriyudthsak, ${ }^{2}$ and Yuji Miyahara ${ }^{{ }^{*}}$ \\ ${ }^{1}$ Institute of Biomaterials and Bioengineering, Tokyo Medical and Dental University, Tokyo 101-0062, Japan \\ ${ }^{2}$ Department of Electrical Engineering, Chulalongkorn University, Bangkok 10330, Thailand
}

(Received August 31, 2017; accepted March 28, 2018)

Keywords: iridium oxide, $\mathrm{pH}$ microsensor

In this study, we evaluate the thermal oxidization methods of iridium to simplify the fabrication of $\mathrm{Ir} / \mathrm{IrOx} \mathrm{pH}$ microsensors. Iridium oxide ( $\mathrm{IrOx}$ ) is a typical $\mathrm{pH}$-sensing material. Specifically, three parameters of the previously reported "carbonate-melt" method are modified, namely, the oxidization temperature, oxidization time, and annealing process after oxidization. Then, we compare the characteristics of the fabricated sensors (i.e., the initial $\mathrm{pH}$ responsivity, time required to reach the steady state, and potential drift). The $\mathrm{pH}$ response depends on oxidization temperature and time.

\section{Introduction}

Proton kinetics is the main indicator for understanding numerous biological and chemical reactions. ${ }^{(1)}$ In the field of biosensors, $\mathrm{pH}$ sensors are essential tools as transducers because many reactions in biomechanisms are $\mathrm{pH}$-dependent. Moreover, $\mathrm{pH}$ is also an indicator for the reaction rate of an electron transfer by-product. ${ }^{(2-4)}$ As a conventional sensor to measure $\mathrm{pH}$ in vitro, glass-type $\mathrm{pH}$ electrodes have been used for decades owing to their simplicity. Many clinical studies have been conducted with glass-type electrodes, ${ }^{(5,6)}$ but some applications such as in vivo studies are incompatible owing to the properties of glass-type electrodes, such as brittleness and size limitations. To overcome these problems, other miniaturized electrodes such as ion-sensitive field-effect transistors (ISFETs) ${ }^{(7)}$ and optical $\mathrm{pH}$ sensors ${ }^{(8,9)}$ have been employed. Although the $\mathrm{pH}$ sensing system with ISFET has attracted attention owing to the small sensing area and fast response, previous studies have revealed that temperature, hysteresis, and drift impact the measurement accuracy. ${ }^{(10-12)}$ Additionally, the photosensing system in optical $\mathrm{pH}$ sensors is limited because more precise instrumentation directly alters the costs.

Generally, metal oxides are excellent proton-sensitive materials. Iridium oxide (IrOx) is a well-known $\mathrm{pH}$-sensitive material. Its properties include proton selectivity, a nearly Nernstian

*Corresponding author: e-mail: miyahara.bsr@tmd.ac.jp

http://dx.doi.org/10.18494/SAM.2018.1733 
$\mathrm{pH}$ response, a fast response time, long-term durability, shape reforming, and nontoxicity of the material. ${ }^{(13,14)}$ These features suggest that IrOx is compatible with clinical studies. Many fabrication techniques have been proposed to improve the $\mathrm{pH}$ selectivity. Examples include sputtering deposition, ${ }^{(15)}$ electrochemical deposition, ${ }^{(16-18)}$ and thermal oxidization. ${ }^{(19)}$ Other studies have applied IrOx in the $\mathrm{pH}$ sensing of organisms. ${ }^{(20,21)}$ In particular, thermal oxidization is stable and durable for long-term usage.

The carbonate-melt method reported by Yao et al. shows a promising $\mathrm{pH}$ responsivity and fast response times. ${ }^{(19)}$ In practice, time is necessary for the sensor to obtain stable potential response data in the steady state after the oxidization process. Moreover, some of the parameters in the fabrication process can be improved.

In this study, we investigated the carbonate-melt ${ }^{(19)}$ fabrication method to improve sensor performance. Since the thickness of the oxide layer affects the robustness of $\mathrm{pH}$ measurements, we systematically examined the effect of three parameters in the fabrication process: oxidization temperature, oxidization time, and annealing process after oxidization. Each parameter was separately varied and the electrochemical characteristics of the $\mathrm{pH}$ sensor were evaluated in terms of $\mathrm{pH}$ responsivity, drift potential at different $\mathrm{pH}$ values, and the time required to achieve a steady state. Compared with conventional methods, the modified method reduced the fabrication time, decreased the drift potential, and reduced the time required to reach the steady state.

\section{Materials and Methods}

\subsection{Materials}

Iridium wire $(\varnothing 0.30 \mathrm{~mm} \times 100 \mathrm{~mm}, 99.9 \%$ purity $)$, gold wire $(\varnothing 0.60 \mathrm{~mm} \times 1 \mathrm{~m}, 99.95 \%$ purity), and silver wire $(\varnothing 0.60 \mathrm{~mm} \times 1 \mathrm{~m}, 99.99 \%$ purity) were purchased from Nilaco, Japan. $\mathrm{Li}_{2} \mathrm{CO}_{3}$ (anhydrous powder, 99.9\% purity) was purchased from Wako Pure Chemical Industries, Japan. Standard $\mathrm{pH}$ solutions with $\mathrm{pH} 4, \mathrm{pH} 7$, and $\mathrm{pH} 9$ ( $\mathrm{pH}$ standard solution set 101-S) were purchased from Horiba, Japan. Ultrapure water (Milli-Q) was supplied by Merck Millipore, USA.

\subsection{Comparison of $\mathrm{Ir} / \mathrm{IrOx} \mathrm{pH}$ sensor fabrication processes}

The oxidization of the iridium wires was conducted as described previously. ${ }^{(22)}$ Briefly, iridium wire (5 mm long and $0.3 \mathrm{~mm}$ diameter) and gold wire $(15 \mathrm{~mm}$ long and $0.6 \mathrm{~mm}$ diameter) were welded with a piezo gas burner. The welded wires were then cleaned using an ultrasonication bath containing acetone followed by ethanol and ultrapure water. After cleaning, the wires were dried in air. The wires were aligned on a gold sheet that covered an alumina crucible. Then, the wires were covered with excess $\mathrm{Li}_{2} \mathrm{CO}_{3}$ powder. On the basis of the original melt carbonate method, the wires were oxidized at $870{ }^{\circ} \mathrm{C}$ for $5 \mathrm{~h}$ and incubated at $120{ }^{\circ} \mathrm{C}$ overnight. To study the effect of fabrication factors, the oxidization temperature was varied from 750 to $950{ }^{\circ} \mathrm{C}$ at a constant oxidization time (Condition 1) or the oxidization time was varied from 1 to $6 \mathrm{~h}$ at a constant oxidization temperature (Condition 2). The wires were 
oxidized in air inside an electric furnace. After cooling the wires to room temperature, the oxidized wires were rinsed with ultrapure water to dissolve the remaining crystallized $\mathrm{Li}_{2} \mathrm{CO}_{3}$. The time necessary for the cleaning process depended on the amount of leftover $\mathrm{Li}_{2} \mathrm{CO}_{3}$. After the oxidization process, we investigated the effect of annealing. The annealing process was conducted at $120{ }^{\circ} \mathrm{C}$ in an incubator overnight, whereas the nonannealing process was performed with the sensor in air. Table 1 summarizes the experimental conditions.

\subsection{Characterization of $\mathrm{pH}$ sensor}

To characterize the $\mathrm{pH}$ sensor, the open-circuit potential between the $\mathrm{pH}$ sensor and the $\mathrm{Ag} /$ $\mathrm{AgCl}$ reference electrode was measured in a standard $\mathrm{pH}$ solution with a Keithley 6514 system electrometer and recorded using the LabVIEW data logging application. Figure 1 illustrates the measurement system. The potential data over time were then calculated for the $\mathrm{pH}$ responsivity and the drift potential.

Table 1

Conditions of three parameters in the fabrication processes: oxidization temperature, oxidization time, and annealing process.

\begin{tabular}{|c|c|c|c|}
\hline Condition & $\begin{array}{l}\text { Oxidization temperature } \\
\left({ }^{\circ} \mathrm{C}\right)\end{array}$ & $\begin{array}{l}\text { Oxidization time } \\
\text { (h) }\end{array}$ & Annealing process \\
\hline Original melt carbonate & 870 & 5 & With annealing \\
\hline (Condition 1) & 750 & \multirow{3}{*}{ Fixed at 5} & \multirow{3}{*}{ With annealing } \\
\hline \multirow{2}{*}{$\begin{array}{l}\text { Varied temperature, } \\
\text { constant time }\end{array}$} & 800 & & \\
\hline & 950 & & \\
\hline \multirow{6}{*}{$\begin{array}{l}\text { (Condition 2) } \\
\text { Varied time, } \\
\text { constant temperature }\end{array}$} & \multirow{6}{*}{ Fixed at 750} & 1 & \multirow{6}{*}{ With annealing } \\
\hline & & 2 & \\
\hline & & 3 & \\
\hline & & 4 & \\
\hline & & 5 & \\
\hline & & 6 & \\
\hline \multirow{3}{*}{$\begin{array}{l}\text { (Condition 3) } \\
\text { Excluding annealing process }\end{array}$} & 750 & \multirow{3}{*}{ Fixed at 5} & \multirow{3}{*}{ Without annealing } \\
\hline & 800 & & \\
\hline & 950 & & \\
\hline
\end{tabular}

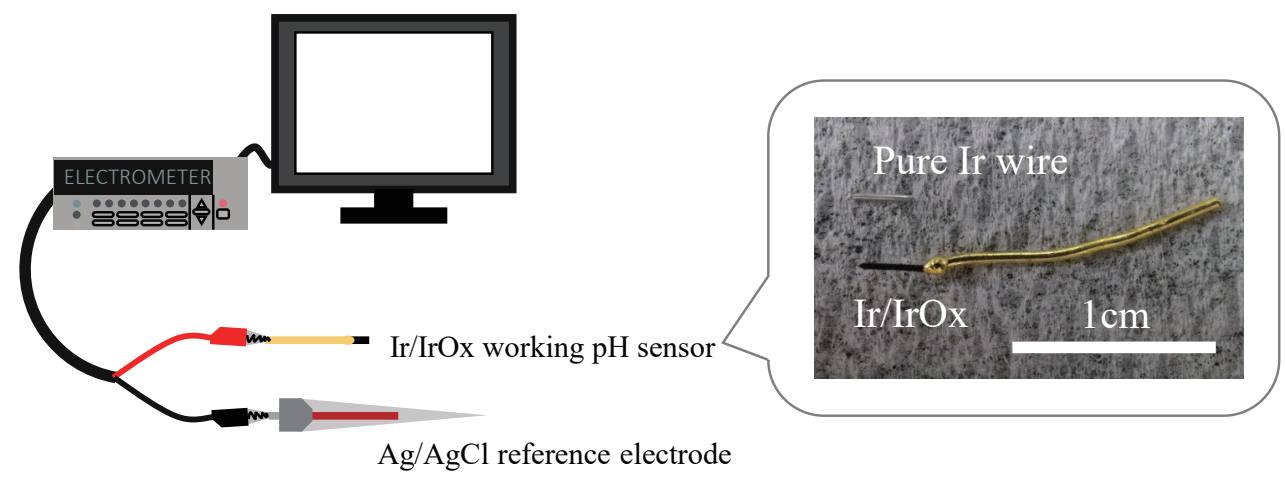

Fig. 1. (Color online) Setup of the open-circuit measurement consisting of an $\mathrm{Ir} / \mathrm{IrOx}$ working $\mathrm{pH}$ sensor, $\mathrm{Ag} /$ $\mathrm{AgCl}$ reference electrode, electrometer, and personal computer with a data logging application. The photograph shows the $\mathrm{Ir} / \mathrm{IrOx} \mathrm{pH}$ sensor and pure Ir prior to oxidization. 
In detail, the $\mathrm{pH}$ responsivity was calculated by averaging the monitoring potential for the last $5 \mathrm{~min}$ in each $\mathrm{pH}$ step response. The averaging potential data sets were plotted against $\mathrm{pH}$. Then, we estimated the slope using linear regression of 3 data points in the $\mathrm{pH}$ range 4 to 9 , or 11 data points in the $\mathrm{pH}$ range 2 to 12 . Drift potentials were calculated from the absolute value of the difference between averaged values of 5 and $10 \mathrm{~min}$ of each $\mathrm{pH}$ step response. The sensor performance and stability improved after several days. The initial $\mathrm{pH}$ responsivity was measured and calculated after the fabrication process was completed. Next, we measured the responsivity of the sensor for several days until the responsivity no longer changed. Then we determined the steady-state $\mathrm{pH}$ responsivity and the time required to reach the steady state. The initial potential drift and steady potential drift are defined as the value of drift taken immediately after fabrication and that taken several days after fabrication, respectively. The proton selectivity was evaluated under the addition of $0.1 \mathrm{M} \mathrm{NaCl}$ to the standard $\mathrm{pH}$ solution. The potential value was recorded in the above manner. The physical properties of the $\mathrm{pH}$ sensor were observed using a scanning electron microscope (SEM) (SU8240, Hitachi HighTechnologies Corporation, Japan). The cross-sectioning of the $\mathrm{pH}$ sensor was performed via rough polishing, fine polishing, and ion milling.

\section{Results and Discussion}

\subsection{Characterization of $\mathrm{Ir} / \mathrm{IrOx}$ electrode}

The electrochemical characteristics of the sensors were evaluated from the $\mathrm{pH}$ responsivity data. Two sensors were evaluated for each condition. Typical raw data of the open-circuit potential are shown in Fig. 2(a). The pH responsivity was calculated from the third cycle of raw data. The calculated $\mathrm{pH}$ response of the sensor is shown in Fig. 2(b). Nernst's equation is expressed as

$$
E=E_{0}-2.303 \frac{R T}{n F} \log H^{+},
$$

where $E$ is the electrode potential, $E_{0}$ is the standard potential, $R$ is the universal gas constant, $T$ is the absolute temperature, $n$ is the electron activity, and $F$ is Faraday's constant.

When $T$ is $25^{\circ} \mathrm{C}$, the theoretical value of the $\mathrm{pH}$ responsivity is $-59.2 \mathrm{mV} / \mathrm{pH}$. Thus, the slopes of the linear functions on varied proton concentrations were evaluated and compared as $\mathrm{pH}$ responsivity. One of the advantages of the $\mathrm{Ir} / \mathrm{IrOx} \mathrm{pH}$ sensor is the proton selectivity. The sensor can neglect the effect of cationic species, and sense only proton activity in solution. The potentiometric response data in Figs. 2(c) and 2(d) showed no difference between with and without the addition of $\mathrm{NaCl}$.

Thermal oxidization obviously changed the iridium portion of the sensor from silver to dark black. The surface morphology of sensors was investigated by SEM (Fig. 3). The $\mathrm{Ir} / \mathrm{IrOx}$ sample shown in the figure was fabricated at an oxidization temperature of $870{ }^{\circ} \mathrm{C}$, an oxidization time of $5 \mathrm{~h}$, and an annealing time of $12 \mathrm{~h}$. The SEM image of the sensor tip shows 


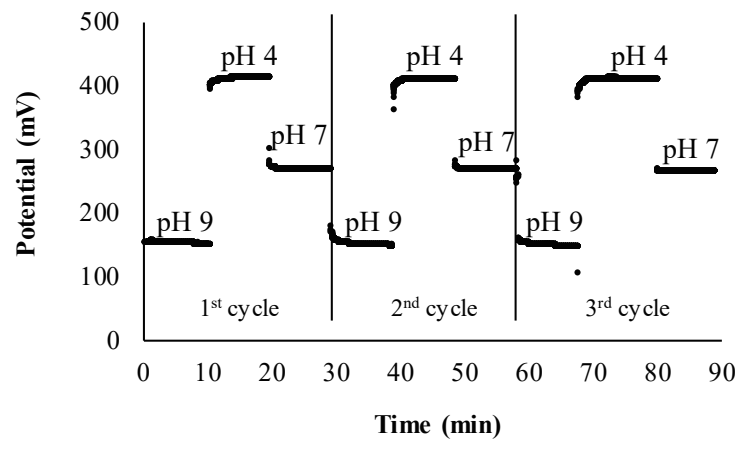

(a)

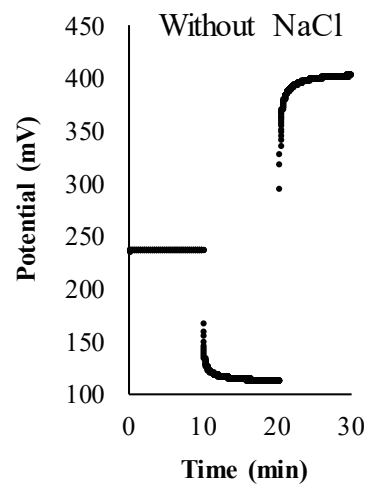

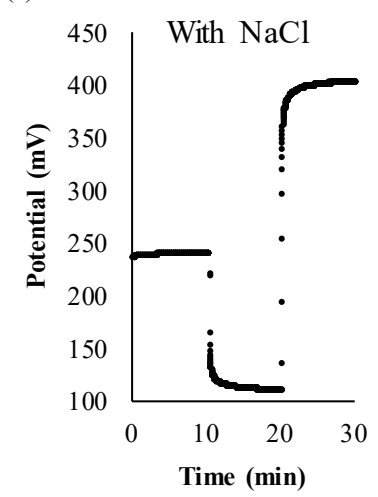

(c)

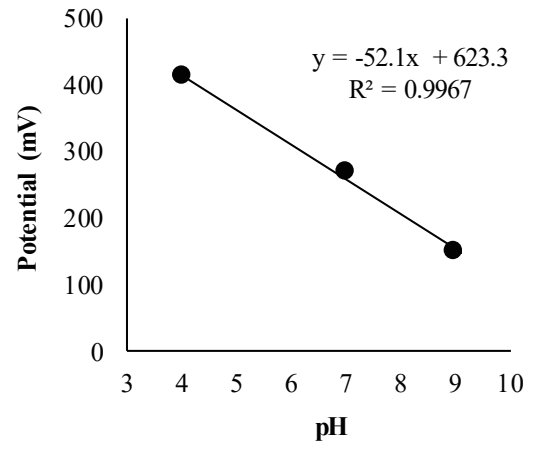

(b)

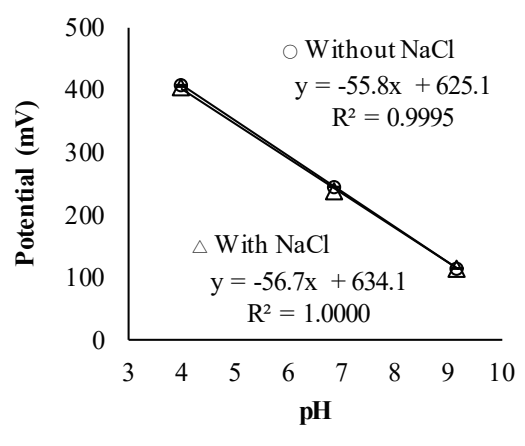

(d)

Fig. 2. Acquiring potential data and evaluation of $\mathrm{pH}$ responsivity: potential responses of the $\mathrm{Ir} / \mathrm{IrOx} \mathrm{pH}$ sensor as a function of (a) time and (b) $\mathrm{pH}$ in the stable state. Potential responses with and without $0.1 \mathrm{M} \mathrm{NaCl}$ as a function of (c) time and (d) $\mathrm{pH}$.

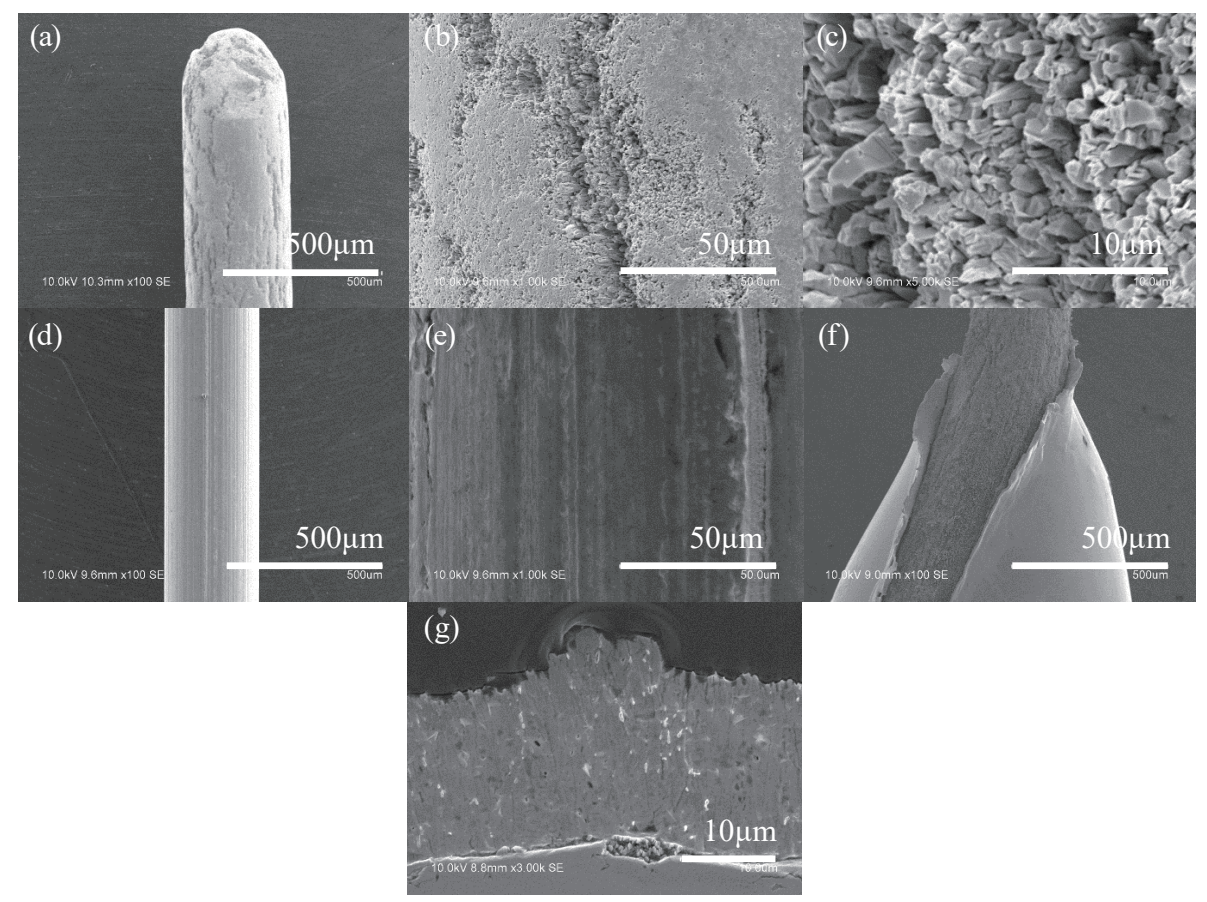

Fig. 3. High-magnification SEM images of the fabricated $\mathrm{Ir} / \mathrm{IrOx} \mathrm{pH}$ sensors: (a, b, c) IrOx tip, (d, e) pure Ir wire, (f) IrOx/Au junction, and (g) cross section of IrOx. 
that the roughness on the whole surface area [Fig. 3(a)] differs from that of the bare iridium surface [Figs. 3(d) and 3(e)]. Additionally, the size and the density of the grains at the surface are nonuniformly distributed; some areas have small pores among the dense oxide surface. The holes of the nonuniform dense surface, which can be seen in Fig. 3(b), show the angular shape of the structure. Figure 3(c) shows the randomness of the grain size on the IrOx surface.

The changes in the surface morphology confirm that the oxide layer is successfully formed around the iridium core. Close-up SEM images of the IrOx/Au junction are shown in Fig. 3(f). The difference in the surface between IrOx and gold reveals that gold is inert to the meltcarbonate thermal oxidization. Figure $3(\mathrm{~g})$ shows cross sections of the sensor. The oxide layer is clearly distinguished from the core iridium wire. The oxide thickness is approximately 20 $\mu \mathrm{m}$ [Fig. 3(g)].

\subsection{Effect of oxidization temperature}

We investigated the effect of the oxidization temperature on the performance of the sensor (Table 2). We varied the oxidization temperature from $750{ }^{\circ} \mathrm{C}$, which is the melting temperature of $\mathrm{Li}_{2} \mathrm{CO}_{3}$, to $950{ }^{\circ} \mathrm{C}$. The initial $\mathrm{pH}$ responsivity of each condition was not close to the theoretical value. The closest value was $-43.8 \mathrm{mV} / \mathrm{pH}$ at a $750{ }^{\circ} \mathrm{C}$ oxidization temperature.

The raw data of the potentiometric response several days after fabrication are shown in Fig. 4(a); the acquiring potential data were unstable. There are potential shifts at each $\mathrm{pH}$

Table 2

Initial $\mathrm{pH}$ responsivity, steady $\mathrm{pH}$ responsivity, and number of days from the initial to the steady state as a function of oxidization temperature with a 5 h oxidization time (Condition 1 in Table 1).

\begin{tabular}{lccc}
\hline $\begin{array}{l}\text { Oxidization } \\
\text { temperature }\left({ }^{\circ} \mathrm{C}\right)\end{array}$ & $\begin{array}{c}\text { Initial } \mathrm{pH} \\
\text { responsivity }(\mathrm{mV} / \mathrm{pH})\end{array}$ & $\begin{array}{c}\text { Steady } \mathrm{pH} \\
\text { responsivity }(\mathrm{mV} / \mathrm{pH})\end{array}$ & $\begin{array}{c}\text { Number of days from } \\
\text { initial to steady state }\end{array}$ \\
\hline 750 & -43.8 & -55.7 & 3 \\
800 & -41.7 & -55.5 & 11 \\
870 & -34.8 & -49.1 & 14 \\
950 & -43.6 & -55.6 & 17 \\
\hline
\end{tabular}

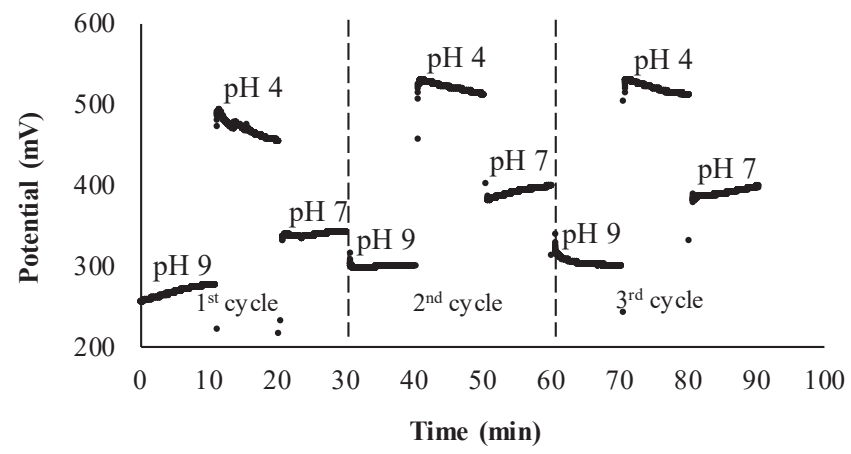

(a)

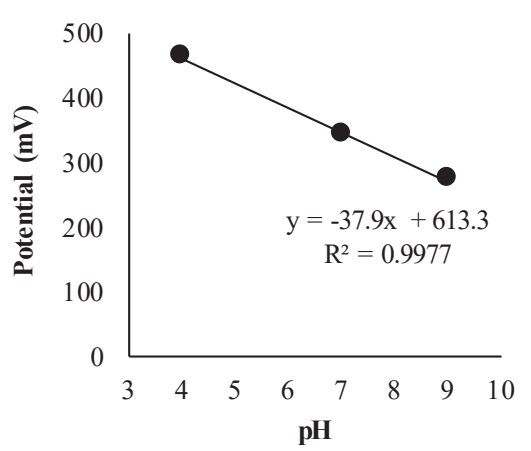

(b)

Fig. 4. Potential responses of the $\mathrm{Ir} / \mathrm{IrOx} \mathrm{pH}$ sensor as a function of (a) time and (b) $\mathrm{pH}$ at initial state. 
value among every period. Furthermore, the $\mathrm{pH}$ responsivity [Fig. 4(b)] was different from that of the ideal $\mathrm{pH}$ sensor. However, after several days, the $\mathrm{pH}$ responsivity improved and approached the ideal responsivity; the value closest to the ideal one was $-55.7 \mathrm{mV} / \mathrm{pH}$ at a $750{ }^{\circ} \mathrm{C}$ oxidization temperature. In some cases, the $\mathrm{pH}$ responsivity plateaued and did not show further improvement, regardless of the passage of time. The $\mathrm{pH}$ responsivity at an $870{ }^{\circ} \mathrm{C}$ oxidization temperature improved from -34.8 and reached a steady state at $-49.1 \mathrm{mV} / \mathrm{pH}$.

The time required for the sensor to reach the steady state was dependent on the conditions. For the $750{ }^{\circ} \mathrm{C}$ condition, the shortest time required was three days. Other conditions needed more than 10 days to reach the steady state. After the oxidization process, the $\mathrm{pH}$ responsivity improved to approximately $-10 \mathrm{mV} / \mathrm{pH}$ and reached a stable value.

The drift potentials of each $\mathrm{pH}$ are shown in Table 3. Among the different oxidization temperatures, the $750{ }^{\circ} \mathrm{C}$ condition showed the lowest potential drift for almost all $\mathrm{pH}$ values in both the initial state and the steady state. In general, every condition showed an improved drift potential after the days passed. Normally, the drift potential phenomenon originates from the transition state from $\operatorname{IrOx}$ to $\operatorname{IrO}(\mathrm{OH})+\mathrm{H}^{+}+\mathrm{e}^{-}$, when the sensor surface is in contact with the aqueous solution phase. ${ }^{(23)}$ We thought that it would take some time to reach equilibrium between $\mathrm{IrOx}$ and $\mathrm{IrO}(\mathrm{OH})$ at the surface. Once the surface of the sensor reaches electrochemical equilibrium, the potential of the sensor becomes stable, while drift of the potential occurs in the middle of the conditioning process before equilibrium.

\subsection{Effect of oxidization time}

Next, we investigated the oxidization time (Table 4). In the comparative study, we used an oxidization temperature of $750{ }^{\circ} \mathrm{C}$, which is the most stable condition, as described in Sect. 3.2. Specifically, we compared the $\mathrm{pH}$ responsivity within three days of fabrication.

The $\mathrm{pH}$ responsivities after an oxidization time of $3 \mathrm{~h}$ were the closest to the ideal condition. The slopes for the two samples were -57.5 and $-58.4 \mathrm{mV} / \mathrm{pH}$. At $2 \mathrm{~h}$, the samples also showed

Table 3

Initial and steady potential drift at different $\mathrm{pH}$ values as a function of oxidization temperature with a $5 \mathrm{~h}$ oxidization time (Condition 1 in Table 1). Two sensor samples were used for each condition.

\begin{tabular}{lccccc}
\hline \multirow{2}{*}{$\begin{array}{l}\text { Oxidization } \\
\text { temperature }\left({ }^{\circ} \mathrm{C}\right)\end{array}$} & $\mathrm{pH}$ value & \multicolumn{2}{c}{$\begin{array}{c}\text { Initial potential drift } \\
(\mathrm{mV} / \mathrm{min})\end{array}$} & \multicolumn{2}{c}{$\begin{array}{c}\text { Steady potential drift } \\
(\mathrm{mV} / \mathrm{min})\end{array}$} \\
\cline { 2 - 6 } & & 1st sample & 2nd sample & 1st sample & 2nd sample \\
\hline 870 & & $4.7 \pm 0.2$ & - & $0.9 \pm 0.6$ & - \\
750 & 4 & $2.2 \pm 0.5$ & $0.5 \pm 0.5$ & $0.4 \pm 0.1$ & $0.2 \pm 0.0$ \\
800 & & $7.7 \pm 1.2$ & $4.0 \pm 2.8$ & $2.4 \pm 2.9$ & $0.2 \pm 0.3$ \\
950 & & $3.4 \pm 1.1$ & $4.1 \pm 2.1$ & $0.8 \pm 0.5$ & $0.5 \pm 0.3$ \\
\hline 870 & & $2.2 \pm 0.2$ & - & $0.6 \pm 0.4$ & - \\
750 & 7 & $0.6 \pm 0.5$ & $2.5 \pm 2.9$ & $0.3 \pm 0.0$ & $0.1 \pm 0.1$ \\
800 & & $3.2 \pm 1.1$ & $2.7 \pm 2.1$ & $0.8 \pm 1.0$ & $0.4 \pm 0.1$ \\
950 & & $2.4 \pm 0.3$ & $2.1 \pm 1.4$ & $0.4 \pm 0.1$ & $0.3 \pm 0.3$ \\
\hline 870 & & $1.3 \pm 0.7$ & - & $0.7 \pm 0.3$ & - \\
750 & 9 & $1.3 \pm 1.4$ & $2.1 \pm 2.9$ & $0.4 \pm 0.1$ & $0.4 \pm 0.0$ \\
800 & & $3.0 \pm 2.9$ & $0.8 \pm 0.8$ & $2.1 \pm 0.6$ & $0.8 \pm 0.5$ \\
950 & & $2.8 \pm 1.3$ & $0.7 \pm 0.6$ & $0.4 \pm 0.5$ & $0.9 \pm 0.4$ \\
\hline
\end{tabular}


Table 4

$\mathrm{pH}$ responsivities after three days of oxidation as a function of oxidization time at a constant oxidization temperature of $750{ }^{\circ} \mathrm{C}$ (Condition 2 in Table 1). Two sensor samples were used for each condition.

\begin{tabular}{lcc}
\hline $\begin{array}{l}\text { Oxidization } \\
\text { time (h) }\end{array}$ & \multicolumn{2}{c}{$\mathrm{pH}$ responsivity $(\mathrm{mV} / \mathrm{pH})$} \\
\cline { 2 - 3 } & 1st sample & 2nd sample \\
\hline 1 & $-41.0 \pm 5.0$ & $-49.8 \pm 2.0$ \\
2 & $-54.0 \pm 3.5$ & $-53.4 \pm 0.8$ \\
3 & $-57.5 \pm 1.0$ & $-58.4 \pm 0.9$ \\
4 & $-41.2 \pm 2.9$ & $-55.3 \pm 1.2$ \\
5 & $-43.5 \pm 1.2$ & $-44.6 \pm 1.8$ \\
6 & $-47.0 \pm 4.3$ & $-47.9 \pm 3.8$ \\
\hline
\end{tabular}

-54.0 and $-53.4 \mathrm{mV} / \mathrm{pH}$, which are also close to the theoretical value. In the $4 \mathrm{~h}$ oxidization, one of the samples showed good $\mathrm{pH}$ responsivity, which is considered to be a result of the improvement of the fabrication process. As seen in the potential drift data (Table 5), an oxidization time of $3 \mathrm{~h}$ showed the smallest magnitude of the potential drift, which was almost zero under all conditions. The $2 \mathrm{~h}$ condition also showed small drift potential for most of $\mathrm{pH}$ values. One sample of $4 \mathrm{~h}$ oxidization showed low drift potential at every $\mathrm{pH}$ value, which supported the improvement. The characteristics of the sensors were not determined after an oxidization time of $1 \mathrm{~h}$, as we assumed that this was an insufficient reaction time to form a complete thick and dense oxide layer.

Among the different oxidization times, the $3 \mathrm{~h}$ condition showed the optimum $\mathrm{pH}$ responsivity and the lowest potential drift for all $\mathrm{pH}$ values in the two samples with the initial state and the steady state. The $2 \mathrm{~h}$ condition also showed the small potential drift but not as well as the $3 \mathrm{~h}$ condition. That of the $4 \mathrm{~h}$ condition also showed further improvement. However, another sample of the $4 \mathrm{~h}$ condition did not meet the requirement of both $\mathrm{pH}$ responsivity and potential drift to give a better yield effect than those of 2 and $3 \mathrm{~h}$. A reliable fabrication method that results in a better time effect would be worthwhile.

\subsection{Effect of annealing process}

After determining the optimum condition for the oxidization process, we evaluated the impact of the postfabrication process. Specifically, we investigated the effect of annealing at $120{ }^{\circ} \mathrm{C}$ after oxidization. Table 6 shows the difference in $\mathrm{pH}$ responsivity with and without the postannealing process. Overall, the nonannealing group showed a $\mathrm{pH}$ responsivity closer to the theoretical value. Table 7 shows the impact of annealing on drift potentials. Although there was a large variation in drift potentials between samples, the differences between the two conditions were very small. These results indicate that the postannealing process is unnecessary. After all the parameters were determined, the wide range of the $\mathrm{pH}$ responsivity from 2 to 12 was confirmed to ensure the linear response. The potentiometric reading of 11 $\mathrm{pH}$ values is shown in Fig. 5(a). The $\mathrm{pH}$ responsivity calculated from the linear regression of 11 points of $\mathrm{pH}$ is $-57.1 \mathrm{mV} / \mathrm{pH}$, as displayed in Fig. 5(b). Considering the calibration curves under the stable condition, the linearity and the fitting regression coefficient $\left(R^{2}\right)$ are 0.9990 to 1.0000 . 
Table 5

Potential drift after three days of oxidation at different $\mathrm{pH}$ values as a function of oxidization time at a constant oxidation temperature of $750^{\circ} \mathrm{C}$ (Condition 2 in Table 1). Two sensor samples were used for each condition.

\begin{tabular}{lccc}
\hline \multirow{2}{*}{$\begin{array}{l}\text { Oxidization } \\
\text { time (h) }\end{array}$} & \multirow{2}{*}{$\mathrm{pH}$ value } & \multicolumn{2}{c}{ Potential drift (mV/min) } \\
\cline { 2 - 3 } 1 & & $3.3 \pm 1.0$ & $1.8 \pm 0.1$ \\
2 & & $0.9 \pm 0.9$ & $0.3 \pm 0.2$ \\
3 & 4 & $0.2 \pm 0.2$ & $0.3 \pm 0.1$ \\
4 & & $2.1 \pm 0.7$ & $0.2 \pm 0.1$ \\
5 & & $2.3 \pm 0.5$ & $0.5 \pm 0.5$ \\
6 & & $1.3 \pm 0.6$ & $2.5 \pm 1.1$ \\
\hline 1 & & $1.2 \pm 0.9$ & $0.3 \pm 0.2$ \\
2 & & $0.7 \pm 0.3$ & $0.3 \pm 0.2$ \\
3 & 7 & $0.1 \pm 0.0$ & $0.0 \pm 0.0$ \\
4 & & $0.7 \pm 0.5$ & $2.5 \pm 2.9$ \\
5 & & $0.9 \pm 0.3$ & $1.3 \pm 1.7$ \\
6 & & $0.7 \pm 0.1$ & $0.5 \pm 0.0$ \\
\hline 1 & & $1.3 \pm 1.0$ & $0.2 \pm 0.2$ \\
2 & & $0.3 \pm 0.2$ & $0.1 \pm 0.1$ \\
3 & 9 & $0.8 \pm 0.9$ & $0.7 \pm 0.5$ \\
4 & & $1.3 \pm 1.4$ & $2.1 \pm 2.9$ \\
5 & & $0.8 \pm 0.2$ & $1.4 \pm 1.4$ \\
6 & & &
\end{tabular}

Table 6

Effects of the postfabrication process (annealing vs nonannealing) on $\mathrm{pH}$ responsivity after three days of oxidization at different $\mathrm{pH}$ values as a function of oxidization temperature with a $5 \mathrm{~h}$ oxidization time (Condition 3 in Table 1). Two sensor samples were used for each condition.

\begin{tabular}{lcccc}
\hline \multirow{2}{*}{$\begin{array}{l}\text { Oxidization } \\
\text { temperature }\left({ }^{\circ} \mathrm{C}\right)\end{array}$} & \multicolumn{2}{c}{$\mathrm{pH}$ responsivity } & \multicolumn{2}{c}{$\mathrm{pH}$ responsivity } \\
& with annealing $(\mathrm{mV} / \mathrm{pH})$ & with nonannealing $(\mathrm{mV} / \mathrm{pH})$ \\
\hline 870 (control) & $-28.0 \pm 6.7$ & - & - & - \\
750 & $-43.5 \pm 1.2$ & $-55.1 \pm 1.8$ & $-53.2 \pm 2.1$ & $-51.0 \pm 2.5$ \\
800 & $-33.3 \pm 9.5$ & $-44.0 \pm 3.8$ & $-45.3 \pm 2.9$ & $-43.3 \pm 2.3$ \\
950 & $-33.0 \pm 10.3$ & $-39.6 \pm 13.6$ & $-45.8 \pm 8.4$ & $-48.8 \pm 2.7$ \\
\hline
\end{tabular}

Table 7

Effects of the postfabrication process (annealing vs nonannealing) on potential drift after three days of oxidization at different $\mathrm{pH}$ values as a function of oxidization temperature with a $5 \mathrm{~h}$ oxidization time (Condition 3 in Table 1). Two sensor samples were used for each condition.

\begin{tabular}{lccccc}
\hline \multirow{2}{*}{$\begin{array}{l}\text { Oxidization } \\
\text { temperature }\left({ }^{\circ} \mathrm{C}\right)\end{array}$} & $\mathrm{pH}$ value & \multicolumn{2}{c}{$\begin{array}{c}\text { Potential drift } \\
\text { with annealing }(\mathrm{mV} / \mathrm{min})\end{array}$} & \multicolumn{2}{c}{$\begin{array}{c}\text { Potential drift } \\
\text { with nonannealing }(\mathrm{mV} / \mathrm{min})\end{array}$} \\
\cline { 2 - 6 } & & $\begin{array}{l}\text { 1st sample } \\
\text { 2nd sample }\end{array}$ & 1st sample & 2nd sample \\
\hline 870 & & $2.7 \pm 0.2$ & - & - & - \\
750 & 4 & $7.7 \pm 1.2$ & $4.0 \pm 2.8$ & $2.6 \pm 3.1$ & $0.7 \pm 0.3$ \\
800 & & $3.4 \pm 1.1$ & $4.1 \pm 2.1$ & $7.2 \pm 3.7$ & $6.4 \pm 5.9$ \\
950 & & $2.2 \pm 0.2$ & - & - & - \\
870 & 7 & $0.6 \pm 0.5$ & $2.5 \pm 2.9$ & $1.0 \pm 0.7$ & $0.7 \pm 0.5$ \\
750 & & $3.2 \pm 1.1$ & $2.7 \pm 2.1$ & $1.4 \pm 0.6$ & $0.7 \pm 0.2$ \\
800 & & $2.4 \pm 0.3$ & $2.1 \pm 1.4$ & $1.6 \pm 1.9$ & $0.9 \pm 1.1$ \\
950 & & $1.3 \pm 0.7$ & - & - & - \\
\hline 870 & 9 & $1.3 \pm 1.4$ & $2.1 \pm 2.9$ & $1.6 \pm 0.4$ & $1.8 \pm 1.6$ \\
750 & & $3.0 \pm 2.9$ & $0.8 \pm 0.8$ & $1.5 \pm 0.3$ & $1.0 \pm 0.1$ \\
800 & & $2.8 \pm 1.3$ & $0.7 \pm 0.6$ & $1.5 \pm 1.1$ & $1.3 \pm 0.5$ \\
950 & & & & &
\end{tabular}




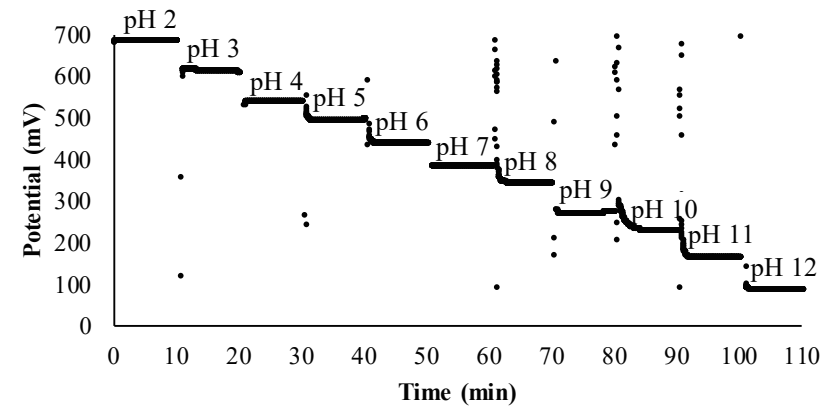

(a)

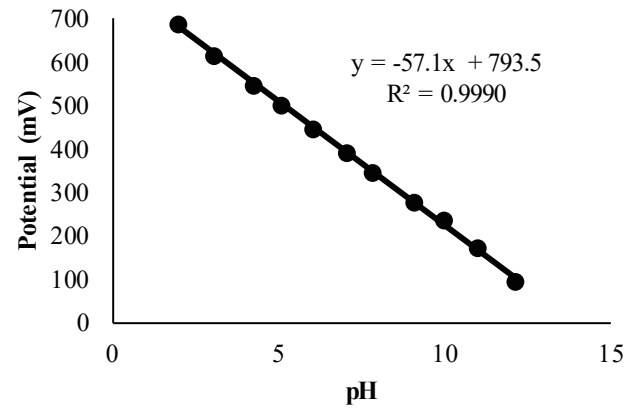

(b)

Fig. 5. Potential responses of $11 \mathrm{pH}$ values from 2 to 12 of the $750{ }^{\circ} \mathrm{C} 3 \mathrm{~h}$ oxidization $\mathrm{Ir} / \mathrm{IrOx} \mathrm{pH}$ sensor as a function of (a) time and (b) 11 points $\mathrm{pH}$ calibration curve.

This study reveals that the $\mathrm{Ir} / \mathrm{IrOx}$ fabrication process can be optimized by employing an oxidization temperature of $750{ }^{\circ} \mathrm{C}$ for $3 \mathrm{~h}$ without postannealing. The lower temperature and the shorter time should directly affect the thickness of the oxide layer. We assume that the thinner oxide layer would reach equilibrium at the surface more rapidly. These results indicate that the enhanced fabrication process not only has shorter fabrication time but also that less time is required for the sensor to reach a steady state. Beyond this fundamental study, further clinical studies should provide a better understanding toward acquiring robust $\mathrm{pH}$ measurements even in environments with many contaminants such as body fluid.

\section{Conclusions}

We successfully improved the sensor fabrication process by considering the fabrication temperature, the duration of the oxidization process, and the time required to reach the steady state. The optimum oxidization temperature in this study $\left(750{ }^{\circ} \mathrm{C}\right)$ resulted in enhanced initial $\mathrm{pH}$ responsivity and the shortest time to reach the steady state. The optimum oxidization time was $3 \mathrm{~h}$. Additionally, a postfabrication process was unnecessary since annealing did not improve sensor characteristics. This simplified oxidization method not only reduces the fabrication time but also enables reliable $\mathrm{pH}$ measurements.

\section{Acknowledgments}

This work was supported financially in part by the Center of Innovation Program from the Japan Science and Technology Agency, JST and the Ministry of Education, Culture, Sports, Science and Technology (MEXT) as part of the Research Center for Biomedical Engineering. The authors thank Professor Isamu Yuitoo of the Research Organization for Nano \& Life Innovation, Waseda University. 


\section{References}

1 S. Adler, A. Roy, and A. S. Relman: J. Clin. Invest. 44 (1965) 21.

2 H. J. Bright and M. Appleby: J. Biol. Chem. 244 (1969) 3625.

3 M. K. Weibel and H. J. Bright: J. Biol. Chem. 246 (1971) 2734.

4 L. Mu, I. A. Droujinine, N. K. Rajan, S. D. Sawtelle, and M. A. Reed: Nano Lett. 14 (2014) 5315.

5 R. Sahney, B. K. Puri, and S. Anand: Anal. Chim. Acta 542 (2005) 157.

6 R. Sahney, S. Anand, B. K. Puri, and A. K. Srivastava: Anal. Chim. Acta 578 (2006) 156.

7 C. S. Lee, S. K. Kim, and M. Kim: Sensors (Basel) 9 (2009) 7111.

8 W. Jin, L. Wu, Y. Song, J. Jiang, X. Zhu, D. Yang, and C. Bai: IEEE Trans. Biomed. Eng. 58 (2011) 1232.

9 W. Jin, J. Jiang, X. Wang, X. Zhu, G. Wang, Y. Song, and C. Bai: Respir. Physiol. Neurobiol. 177 (2011) 183.

10 S. Jamasb, S. Collins, and R. L. Smith: Sens. Actuators, B 49 (1998) 146.

11 J. C. Chou and C. N. Hsiao: Sens. Actuators, B 66 (2000) 181.

12 J. L. Chiang, S. S. Jan, J. C. Chou, and Y. C. Chen: Sens. Actuators, B 76 (2001) 624.

13 S. C. Mailley, M. Hyland, P. Mailley, J. M. McLaughlin, and E. T. McAdams: Mater. Sci. Eng. C 21 (2002) 167.

14 I. S. Lee, C. N. Whang, Y. H. Lee, G. Hwan Lee, B. J. Park, J. C. Park, W. S. Seo, and F. Z. Cui: Thin Solid Films 475 (2005) 332.

15 Y. Pan, T. Noda, K. Sasagawa, T. Tokuda, H. Kanda, T. Fujikado, and J. Ohta: J. Phys. Conf. Ser. 352 (2012) 012005.

16 T. Y. Kim and S. Yang: Sens. Actuators, B 196 (2014) 31.

17 J. Park, M. Kim, and S. Kim: Sens. Actuators, B 204 (2014) 197.

18 X. Huang, Q. Ren, X. Yuan, W. Wen, W. Chen, and D. Zhan: Electrochem. Commun. 40 (2014) 35.

19 S. Yao, M. Wang, and M. Madou: J. Electrochem. Soc. 148 (2001) H29.

20 W. D. Huang, H. Cao, S. Deb, M. Chiao, and J. C. Chiao: Sens. Actuators, A 169 (2011) 1.

21 R. Sheybani and A. Shukla: Biosens. Bioelectron 92 (2017) 425.

22 M. Wang, S. Yao, and M. Madou: Sens. Actuators, B 81 (2002) 313.

23 W. Olthuis, M. A. M. Robben, P. Bergveld, M. Bos, and W. E. van der Linden: Sens. Actuators, B 2 (1990) 247. 